\title{
An evaluation of surgical treatment for spinal cord compression due to metastatic carcinoma
}

\author{
RODERICK SMITH
}

\author{
From the Departments of Neurology and Neurosurgery of The London Hospital
}

The rising incidence of neoplastic disease in the past three decades (Registrar General, 1962), coupled with improvement in surgical and medical treatment, has resulted in an increasing number of patients with malignant deposits in an around the spinal cord being referred for surgical evaluation. The management of these cases has given rise to considerable discussion.

Laminectomy and decompression in all cases of spinal cord compression is advocated by Perese (1958), Rogers (1958), and Dinning (1961) on the grounds that surgery is necessary to establish a diagnosis and that the patient may benefit from the operation. Törmä (1957) reviewed 250 case histories from Scandinavian hospitals and concluded that surgery was unlikely to result in a remission of symptoms, but that patients should nonetheless be offered a laminectomy and decompression.

Other authors, notably Elsberg (1941), Rasmussen, Kernohan, and Adson (1940), and Arseni, Simionescu, and Horwath (1959), have emphasized that most cases of paresis or paralysis are not improved by operation, and that when the compression is clearly caused by a malignant secondary deposit surgery should be directed at the relief of pain. Laminectomy and decompression should be considered only as one of the methods which might be employed to make the patient comfortable. The general acknowledgement of a poor prognosis in this condition has led to attempts to differentiate preoperatively those patients who are likely to be helped by operation from those who are not.

Barron, Hirano, Araki, and Terry (1959) tried to separate those patients who were not likely to be helped by surgery on the basis of the clinical picture and the pathology of the primary. Reviewing 38 cases, they concluded that operation is unlikely to prove valuable where the patient exhibits a flaccid paraplegia, where sensory loss is complete, where total paraplegia has developed in less than 72 hours, or where the primary tumour is a carcinoma of the lung.

A different point of view is put forward by Larson, Wetzel, Brochner, and Ruge (1961), who reviewed 23 cases, and concluded that although laminectomy does not improve most patients, it may arrest the $\frac{\overline{ }}{\overline{0}}$ course of the compression and preserve any remain- $-\frac{\bar{T}}{\Phi}$ ing function.

It is understandable that this difference of opinion should exist. Many reported series consist of a relatively small number of patients with widely? varying types of primary tumour. Carcinomas, $\vec{\omega}$ sarcomas, leukaemias and lymphomas, and myelo- $\stackrel{\sigma}{-}$ mata are frequently considered together. The number $\overline{\vec{T}}$ of individual cases of each type is not large, and the part played by surgery in determining a successful $i_{\infty}$ or unsuccessful outcome is difficult to assess. hi addition, there is no general agreement as to whके or constitutes significant improvement following operof 0 tion. Some authors consider that a partial return $\mathscr{F}$ 을 motor function, even though the patient remais $\vec{\longrightarrow}$ bedfast, is sufficient justification for the operatiog (Barron et al., 1959; Dinning, 1961; Larson et aP, 1961). Others demand a return to independent amb $\overrightarrow{5}$ lation.

With these considerations in mind it was decided 0 to review cases of spinal cord compression due to carcinoma submitted to operation at the London Hospital. The study was limited to cases of metastatic carcinoma, as the literature contains a number of $\frac{\Phi}{\circ}$ encouraging reports of the beneficial results of laminectomy with or without radiation in cases of $\overrightarrow{\vec{O}}$ multiple myeloma (Svien, Price, and Bayrd, 1953; Clarke, 1956; Jacox and Kahn, 1933; McKissock, 茟 Bloom, and Chynn, 1961). Cases of Hodgkin's disease and lymphosarcoma have been shown to respond equally well either to surgical decompression followed by radiation (Love, Miller, and Roernohan, 1954), or a combination of radiation and chemotherapy (Williams, Diamond, and Craver, 1958).

Fifty-two cases ( 35 men and 17 women) of second- 윽 ary carcinoma were available for analysis. Histological proof of malignancy was obtained in all, but full post-mortem examination was achieved in $N$ only 10 . Two patients are still living, 49 have died, and one was lost to follow-up. A tumour deposit $\mathcal{N}$ corresponding to the level of the lesion was found $\underset{\omega}{N}$ in 51 cases. The remaining patient died during the 
induction of anaesthesia, and permission for necropsy was refused.

Table I gives the site of the primary neoplasm responsible for the spinal cord compression.

TABLE I

PRIMARY SITES OF METASTATIC SPINAL DEPOSITS

\begin{tabular}{lclc} 
Site & No. of Cases & Site & No. of Cases \\
\hline Lung & 12 & Thyroid & 2 \\
Presumed lung & 16 & Skin & 1 \\
Prostate & 4 & Breast & 3 \\
Presumed prostate & 3 & Bladder & 1 \\
Stomach & 1 & Oesophagus & 1 \\
Rectum & 1 & Pancreas & 1 \\
Kidney & 2 & Unknown & 4
\end{tabular}

Precise confirmation of the primary site was possible in 29 cases. Of the remaining 23 , four were classed as secondary carcinoma of unknown origin. The remainder have been grouped according to the presumed primary site, which was determined by the histological nature of the spinal tumour, $x$-ray examination, and the clinical appearance of the patient.

\section{TABLE II}

SITE OF THE LESION IN RELATION TO THE SPINE

\begin{tabular}{lclc} 
Spinal Site & No. of Cases & Spinal Site & No. of Cases \\
\hline Cervical & 5 & Thoraco-lumbar & 1 \\
Cervico-thoracic & 2 & Lumbar & 10 \\
Thoracic & 33 & Sacral & 1
\end{tabular}

Table II shows the site of the lesion in relation to the spinal column. In seven cases the tumour involved the cord over four adjacent segments, in seven cases over three, and in eight cases over two. In the remainder the tumour deposit was found at a single level. In 48 cases the deposit was extradural, in two cases it was intradural, and in one, in addition to a large extradural tumour involving bone, a small intradural deposit was found. Thirty-three cases had gross involvement of vertebral bodies at the level of the lesion.

In one patient a partially extruded intramedullary secondary deposit from a bronchogenic primary was discovered at operation. At necropsy this patient was found to have developed carcinomatous meningitis with spread of the tumour caudally along the surface of the cord. Another example of intradural metastases proved to have diffuse involvement of the cauda equina. With the exception of this case, where the diagnosis of carcinomatous meningitis was made before operation, surgery was undertaken in the hope of removing any tumour encountered and decompressing the cord.

Sixteen cases were known to have carcinoma before the development of symptoms of spinal cord compression, and eight of these presented with secondary deposits at extraspinal sites. In an additional 14 cases, the presence of primary carcinoma was discovered during the course of pre-operative investigation. In the remaining 22 cases, the nature of the compressing tumour was unknown.

The clinical picture in the majority of patients was remarkably similar. Thirty-nine presented with the complaint of radicular pain of increasing severity followed in weeks or months by the development of weakness, sphincter disturbance, and areas of sensory loss or paraesthesia below the level of the lesion. Of the 13 cases which might be considered atypical, five presented with paraesthesia and numbness, three with weakness, one with funicular pain, one with a dull, aching back pain, and one case developed radicular pain and weakness simultaneously. In two cases radicular pain was the only complaint, and no neurological abnormalities were found on examination. In all cases the symptoms were progressive.

On examination 50 patients were found to have a combination of weakness and sensory loss. In 12, this took the form of cord transection with complete paraplegia, incontinence, and a dense sensory loss below the level of the lesion. Nine patients had complete motor loss but retained some appreciation of sensation. In the remainder, neither weakness nor sensory loss was complete.

There was considerable variation in the duration of symptoms before operation. It was generally shorter in patients with a primary growth in the lung. In these the mean duration of symptoms was 11 weeks as compared with 23 weeks in the prostatic group and 13 weeks in the other tumours. Figure 1 shows the individual cases from the onset of symptoms until the time of operation. It can be seen that seven of the 12 cord transactions became complete in less than 72 hours. In one case this followed lumbar puncture. Similarly, two of the nine cases with complete paraplegia but incomplete sensory loss became so in the same period of time.

Twenty-three patients exhibited a flaccid type of weakness, and in 14 of these the site of the primary tumour was the lung. In three, the primary was prostatic and the remaining seven were divided between five primary sites. Seven of the patients with flaccid weakness had no radicular pain, but complained of a dull aching back pain made worse by movement. Forty-six patients were generally fit at the time of operation. The remaining six were described as wasted and ill-looking, and had developed infected pressure sores.

Radiographs of the spine were obtained in all cases, and myelography, by either the lumbar or 


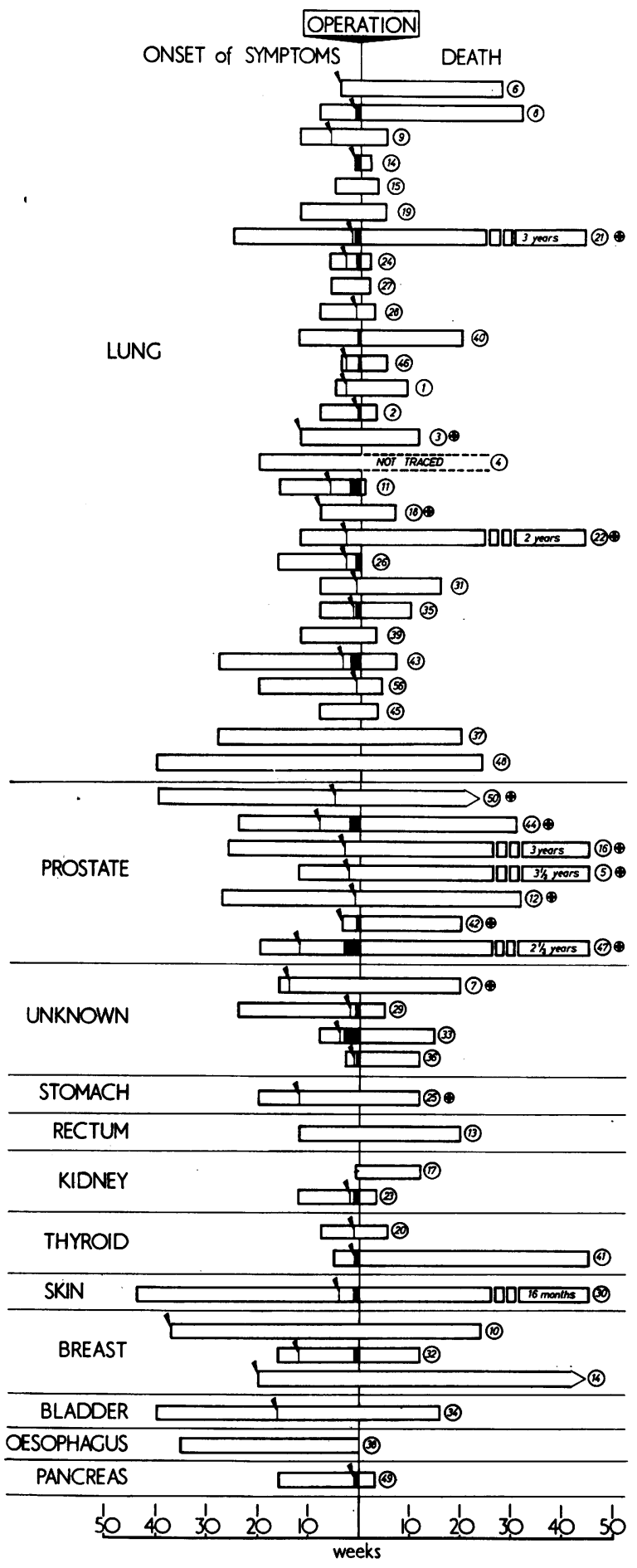

cisternal route or by a combination of both, was performed in 35. A block to the passage of conftast media was demonstrated in 33 , and a filling derect in the remaining two. Collapse of one or more vertebral bodies at the site of the lesion was revealed in 14 cases.

Post-mortem examination was obtained in 10 patients in this series. The majority of these died in hospital soon after operation, and this selection contains an obvious bias. On examination only one case proved to have a solitary metastasis at the spinal site. In the others the tumour had spread to at least one additional site, and in three cases there was widespread dissemination.

As mentioned previously, one patient was submitted to operation in order to confirm the diagnosis of carcinomatous meningitis, which proved to be correct. In the remaining 51 , surgery was undertaken in the hope of effecting a regression of symptoms and signs and a return to useful activity. There were two operative deaths; one following the induction of anaesthesia and the other during the operation.

The record of the remaining 49 is summarized in Table III.

\section{TABLE III}

RESULTS OF LAMINECTOMY AND DECOMPRESSION WITH REMOVAL OF THE SPINAL TUMOUR

\begin{tabular}{|c|c|c|c|c|c|}
\hline Lost to follo & & & & & \\
\hline Surviving m & than si & $\mathbf{x} \mathbf{w}$ & & & 32 \\
\hline Surviving m & than $2 C$ & w & & & \\
\hline Minimally in & oved & $\cdots$ & $\cdots$ & $\cdots$ & \\
\hline Significantly & proved & .. & . & . & 1 \\
\hline Made worse & $\ldots$ & .. & .. & . & \\
\hline Unchanged & . & .. & .. & . & \\
\hline
\end{tabular}

\section{DISCUSSION}

Assessment following operation showed that 21 patients could be considered improved in that there was some regression of symptoms and signs, but in eight of these this was minimal and consisted only of an increased appreciation of sensation or the ability to initiate weak voluntary movements of the previously paralysed limbs. Thirteen were significantly improved, that is, they were restored to independent walking with or without the aid of sticks or crutches. Comparison of the two groups revealed that none

FIG. 1. Individual cases of carcinomatous spinal cord compression grouped according to the nature of the primary tumour. The presence and duration of paraplegia is indicated by shading. Black shading represents a functional transection of the cord while those cases with complete paraplegia but an incomplete loss of the ability to perceive sensation are indicated by cross-hatching. $A$ wedge-shaped mark indicates the onset of weakness. $A$ cross within a circle denotes those patients showing significant improvement. 
of the 16 surviving less than six weeks made a significant recovery and four were minimally improved. It is possible that these patients might have continued to improve had they not been harbouring a rapidly progressing carcinoma. Fisher (1963) states that the early return of sensory function following laminectomy indicates a good prognosis. It may be that the debilitation and cachexia which accompany the terminal stages of malignant disease produce metabolic changes in the damaged cord inhibiting a return of function. Tarlov (1957) has noted how animals which had completely recovered from experimental paraplegia could become paralysed once again if suffering from severe systemic infection or failing health. Alternatively, they were simply overtaken by the primary disease before significant recovery could take place. Whatever the reason, the only encouraging results were found among the 32 patients surviving longer than six weeks; of these, 13 made a good recovery. Five of these, however, died within the next 14 weeks, leaving among the 16 long-term survivors, only eight who could be described as significantly improved by operation (Table IV).

Surgical intervention then was of little benefit to the majority of patients included in this series, but it is useful to consider what factors may differentiate those cases which were helped by operation from those which were not.

\section{TABLE IV}

RESULTS OF LAMINECTOMY IN METASTATIC CARCINOMA

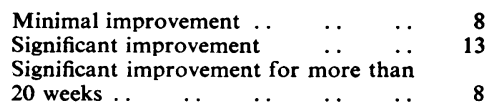

TABLE V

RESUlts AS A FUNCTION OF THE ClinicAl PICTURE

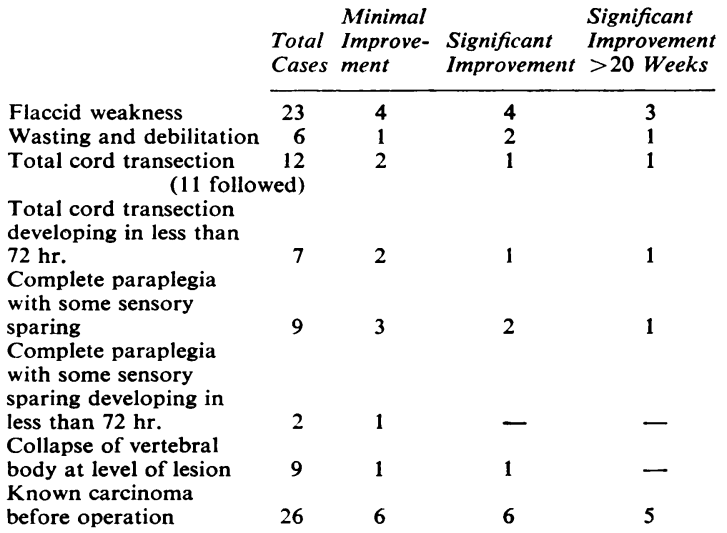

Table $\mathrm{V}$ displays the results in 48 cases as a function of factors which could be assessed pre-operaatively and which have been reported to be of prognostic value.

It is apparent that in patients with known carcinoma before operation, or flaccid weakness, the incidence of improvement is approximately that of the series as a whole. The total number of cases in each of the other groups is too small to permit any significant conclusions, but it should be noted that neither severe wasting, total cord transection developing in less than 72 hours, nor collapse of a vertebral body at the site of compression, precluded a successful result. The level of the lesion in the spine did not apparently significantly influence the outcome as the distribution of improved cases (Table VI) resembles the overall distribution shown in Table II.

\section{TABLE VI}

LEVEL OF THE LESION IN CASES SHOWING IMPROVEMENT AFTER SURGERY

\begin{tabular}{lrccc} 
Level of Lesion & $\begin{array}{l}\text { Total } \\
\text { Cases }\end{array}$ & $\begin{array}{l}\text { Minimal } \\
\text { Improve- }\end{array}$ & $\begin{array}{l}\text { Significant } \\
\text { Improvement }\end{array}$ & $\begin{array}{l}\text { Significant } \\
\text { Improvement } \\
>20 \text { Weeks }\end{array}$ \\
\hline Cervical & 5 & 1 & - & - \\
Cervico-thoracic & 2 & 2 & 1 & 1 \\
Thoracic & 33 & 4 & 10 & - \\
Thoraco-lumbar & 1 & - & - & - \\
Lumbar & 10 & 1 & 2 & - \\
Sacral & 1 & 1 & - & 8 \\
Total & 52 & 8 & 13 &
\end{tabular}

More interesting, however, is a consideration of the results grouped according to the site of the primary lesion (Table VII); the outstanding feature is that all the cases of carcinoma of the prostate were significantly improved.

\section{TABLE VII}

RESULTS AS A FUNCTION OF THE PRIMARY SITE

\begin{tabular}{lrccc} 
Site of Primary & $\begin{array}{c}\text { Total } \\
\text { No. }\end{array}$ & $\begin{array}{l}\text { Minimal } \\
\text { Improve- } \\
\text { ment }\end{array}$ & $\begin{array}{l}\text { Significant } \\
\text { Improvement }\end{array}$ & $\begin{array}{l}\text { Significant } \\
\text { Improvement }\end{array}$ \\
\hline 20 Weeks
\end{tabular}

The number of cases of thyroid, breast, renal, and other tumours shown in Table VII are too small to permit any significant conclusion, but the cases of lung and prostatic metastases can be considered further. 
The results here confirm the unfavourable prognosis of metastases arising from bronchogenic primaries. With two exceptions, surgical intervention in this group was of little value. Aside from the good result, one of these was in no way unusual. The other presented with a six months' history of slowly progressive cord compression and a shadow at the apex of the right lung. One week before operation he became completely paraplegic following a lumbar puncture. Laminectomy and removal of the spinal tumour was followed by a course of radiotherapy to both the spine and the right pulmonary apex. Thoracotomy, four months after the laminectomy, revealed only a carcinomatous pleural nodule. The patient made a good functional recovery, and eventually died two and a half years after the original operation. The duration of preoperative symptoms in this case is more than twice the mean and this, together with the apparent radiosensitivity and peripheral location of the primary, may explain the good result.

The other case illustrates the difficulty involved in attempting to predict the eventual outcome in any individual patient. This man presented with a history of back pain and weakness for three months. Examination revealed a lesion at $\mathrm{T} 5$, and chest radiographs showed a hilar mass extending into the left lower lobe. Following laminectomy and the removal of an extradural carcinomatous deposit, he received a course of radiotherapy to the site of the spinal lesion but none to the primary. There was a rapid return of function to the lower limbs and he remained well and active for the next 20 months, finally succumbing more than two years after the operation from extension and dissemination of the primary.

Thirteen other cases of carcinoma of the lung, with a similar clinical picture, were not helped by operation, and it is difficult to decide why this patient did so well. It may be significant that in both cases cited above the duration of symptoms pre-operatively exceeded the mean for the group. Tarlov (1957) has shown that experimental paraplegia caused by a gradual compression is potentially reversible for a longer period than when caused by an acute lesion. In addition the longer history suggests a biologically less aggressive primary than in those cases where the period between the onset of symptoms and death is only a matter of a few weeks.

\section{TABLE VIII}

RESULTS IN 20 CASES WITH A HISTORY OF PRE-OPERATIVE SYMPTOMS OF EIGHT WEEKS OR LESS

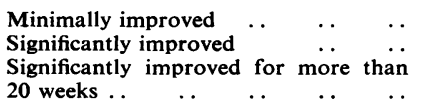

In the case of lung primary, when patients showing $\frac{}{Z}$ any improvement after operation are grouped, it is $\mathbb{C}$ seen that only one of these (case 14) had a preoperative history of less than eight weeks. Excluding $\stackrel{\text { ? }}{\subseteq}$ this case, the mean for the others is 13 weeks, and it $\overline{0}$ seems likely that it is in this group that any possibly $D_{D}$ successful results may be expected. Conversely, a history of eight weeks or less seems to have a most unfavourable prognosis (Table VIII). In this group, of 14 cases of carcinoma of the lung, 12 patients showed no improvement; one was minimally im- $\underset{\vec{S}}{\stackrel{\vec{S}}{\rightarrow}}$ proved, but survived less than two weeks; and the $\overline{0}$ other, while initially significantly improved, rapidly $\frac{5}{0}$ deteriorated and died within seven weeks of opera- $\frac{\bar{c}}{\vec{s}}$ tion. Five other similar cases with metastases from $\mathbb{\mathbb { D }}$ varying primary sites were wholly unimproved. The single case of prostatic carcinoma in this category was also significantly improved, but again the post- $\vec{\circ}$ operative survival was relatively limited and the $\overrightarrow{\vec{\omega}}$ patient died within 20 weeks. It appears that even in $\stackrel{\omega}{\sigma}$ this relatively more benign tumour a short history indicates a poor prognosis.

Generally, however, the cases of prostatic metas- in tases present a very favourable picture of the severp i patients submitted to surgery. All were significant $\frac{P}{i}$ improved. As mentioned, one succumbed within $N$ 20 weeks, but this patient (42) was ill and wastegi and had developed diffuse metastases before opera tion. One patient (50) is still living and shows ne $\frac{D}{0}$ sign of a recurrence of his paresis. The mean suo vival in the remaining patients was 28 months, and $\overrightarrow{0}$ all were ambulatory until a few months beforo of death. Marshall, Tavel, and Schulte (1962) have reported similarly good results in eight of 13 cases of prostatic metastases followed post-operatively for an average of eight and a half months.

The results obtained in these cases most probably reflect the relatively benign nature of the primary tumour. Figure 1 shows that the progression of $\overrightarrow{\overrightarrow{0}}$ symptoms was more gradual. The mean interval 3 between the onset of symptoms and operation was 23 weeks compared with 11 weeks in the lung tumours and 14 weeks in the others. In addition the palliative measures generally employed in the treatment of incurable prostatic carcinoma can be em- $\dot{0}$ ployed in conjunction with laminectomy and removal of the spinal deposit. The beneficial effects of orchi- 8 dectomy and the administration of oestrogens are 3 well known (Goodwin, 1961), and spinal deposits 음 may respond to these measures. The remission of complete paraplegia presumed to be caused by prostatic metastases has been reported following the administration of oestrogens (Edelman, 1949), $\Omega$ and more recently after adrenalectomy (Bowers, $N$ 1962). In addition, prostatic carcinoma is frequently

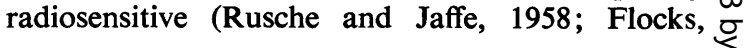


Culp, and Elkins, 1959), and the two patients with the best results in this series received a course of radiotherapy to the site of the spinal lesion following operation.

\section{CONCLUSIONS}

From the cases reviewed here, it appears that while the outlook for patients with carcinomatous cord compression is bleak, it is not hopeless and that very worthwhile results may sometimes be obtained by surgical removal of the spinal deposit. For a number of reasons, laminectomy and decompression with attempted removal of the tumour would appear to be advisable in all but a minority of cases. In nearly half the cases in this study the operation was necessary to establish a diagnosis and, as there was no difference in the success rate in the two groups, the presence of malignancy in a patient suffering from spinal cord compression should not in itself justify a refusal to operate.

The procedure is not hazardous and the operative mortality, considering the nature of the disease, should be generally acceptable. While the majority of patients were unimproved, the number showing marked improvement was nearly twice the total of those made worse, and the fear of increasing the patients' disability should not be considered a significant contraindication.

Another factor which does not in itself justify surgery, but which may make the operation more acceptable to the patient, is that where pain is present and severe it is frequently improved by laminectomy and decompression.

Patients who are not likely to benefit, however, should be spared the stress of an operation. In assessing these cases it appears that a short history of progressive symptoms is the most reliable indication of those who will do badly, and when this is combined with other factors such as flaccid weakness, vertebral collapse, total paraplegia, long-standing paraplegia, or paraplegia of sudden onset, the chances of recovery are very slight. In the absence of a short history, however, the presence of one or more of the other factors should not be grounds for refusing operation. The nature of the primary tumour is also undoubtedly very important in establishing the prognosis. In view of the good results reported here and elsewhere in cases of prostatic metastases, it would seem that surgery should be offered to all but terminal cases. In patients with carcinoma of the lung, the results of surgery are likely to be most disappointing, but the absence of any features which clearly distinguish the rare cases, which both improve and survive, from the majority force the conclusion that surgery is necessary in all cases except those with a short history if the maximum number are to be helped. Other primary tumours are not represented here in sufficient numbers to permit any firm conclusion, but in the absence of any definite evidence it would seem reasonable, as in carcinoma of the lung, to continue to offer operation to all except those with a short history of progressive symptoms and signs.

Finally, although no attempt was made to assess the effects of radiotherapy, it was apparent that many of the patients showing significant improvement had undoubtedly benefited from irradiation of the spinal lesion, and it might be profitable if this were employed following surgery whenever there is a suggestion that the tumour may be radiosensitive.

\section{SUMMARY}

A review of 48 cases of spinal cord compression due to secondary carcinoma submitted to surgery at the London Hospital revealed 13 cases in which there was significant improvement after operation. Of the remainder, eight were slightly improved, 20 unchanged, and seven made worse.

Only 16 patients lived more than 20 weeks after operation. Eight of these were from the group showing significant improvement.

In assessing the prognosis for an individual case, it appears that a short pre-operative history is the most reliable guide to those patients who will show no improvement. In the absence of such a history, signs such as complete paraplegia, long-standing paraplegia, paraplegia of sudden onset, flaccid weakness, vertebral collapse, or severe wasting do not present an insuperable barrier to recovery and should not be grounds for refusing operation. The pathology of the primary tumour is also most important. All patients reported here with carcinoma of the prostate were significantly improved, and operation is recommended in all but terminal cases. Conversely, of 28 cases of carcinoma of the lung only four were significantly improved, but it appears to be impossible to differentiate pre-operatively from the majority the rare case which will improve.

Laminectomy and decompression, with attempted removal of the spinal tumour, is recommended in all cases of spinal cord compression due to secondary carcinoma, except those with a short history of progressive symptoms and signs.

I wish to express my gratitude to Dr. R. A. Henson and Mr. D. W. C. Northfield, both for their advice and for permission to examine their patients.

\section{REFERENCES}

Arseni, C. N., Simionescu, M. D., and Horwath, L. (1959). Tumors of the spine. Acta psychiat. scand., 34, 398-410. 
Barron, K. D., Hirano, A., Araki, S., and Terry, R. D. (1959) Experiences with metastatic neoplasms involving the spinal cord. Neurology (Minneap.), 9, 91-106.

Bowers, R. F. (1962). Adrenalectomy for hopeless carcinoma of the prostate. Arch. Surg., 84, 421-424.

Clarke, E. (1956). Spinal cord involvement in multiple myelomatosis. Brain, 79, 332-348.

Dinning, T. (1961). Malignant spinal extradural tumours. Aust. N.Z. J. Surg., 31, 126-133.

Edelman, I. S. (1949). Paraplegia secondary to metastatic prostatic carcinoma treated with stilbestrol. Ann. intern. Med., 31, 1098.

Elsberg, C. A. (1941). Surgical Diseases of the Spinal Cord, Membranes, and Nerve Roots. Hoeber, New York.

Fisher, A. (1963), Observations on the prognostic signs following relief of spinal cord compression. Proc. Aust Assn. Neurol., 1, 31-34.

Flocks, R. H., Culp, D. A., and Elkins, H. B. (1959). Present status of radioactive gold therapy in management of prostatic cancer. J. Urol. (Baltimore), 81, 178-184.

General Register Office (1964). Registrar General's statistical review of England and Wales for the year 1962. Part 1. Tables, Medical. H.M.S.O., London.

Goodwin, W. E. (1961). Current concepts concerning treatment of cancer of the prostate gland. In Proc. 4th nat. Cancer Conferance, University of Minnesota, 1960, pp. 495-99. Lippincott, Philadelphia.

Jacox, H. W., and Kahn, E. A. (1933). Multiple myeloma with spinal cord involvement. Amer. J. Roentgenol., 30, 201.

Larson, S., Wetzel, N., Brochner, R., and Ruge, D. (1961). The surgical treatment of metastatic epidural tumors. Quart. Bull Northw. Univ. med. Sch., 35, 42-44.
Love, J. G., Miller, R. H., and Roernohan, J. W. (1954). Lymphomas of spinal epidural space. Arch. Surg., 69, 66-76.

McKissock, W., Bloom, W. H., and Chynn, K. Y. (1961). Spinal cord compression caused by plasma-cell tumours. J. Neurosurg., 18, 68-73.

Marshall, S., Tavel, F. R., and Schulte, J. W. (1962). Spinal cord compression secondary to metastatic carcinoma of the prostate treated by decompressive laminectomy. J. Urol. (Baltimore), $88,667-673$.

Perese, D. M. (1958). Treatment of metastatic extradural spinal cord tumors; a series of 30 cases. Cancer (Philad.), 11, 214-221.

Rasmussen, T. B., Kernohan, J. W., and Adson, A. W. (1940). Pathologic classification, with surgical consideration, of intraspinal tumors. Ann. Surg., 111, 513-530.

Rogers, L. (1958). Malignant spinal tumours and the epidural space. Brit. J. Surg., 45, 416-422.

Rusche, C. F., and Jaffe, H. L. (1958). Treatment of bladder and prostatic cancer by combined interstitial isotope radiation and the cobalt bomb. J. Urol. (Baltimore), 79, 474-489.

Svien, H. J., Price, R. D., and Bayrd, E. D. (1953). Neurosurgical treatment of compression of the spinal cord caused by myeloma. J. Amer. med. Ass., 153, 784-786.

Törmä, T. (1957). Malignant tumours of the spine and the spinal extradural space; a study based on 250 histologically verified cases. Acta chir. scand., suppl. 225 pp.

Tarlov, I. M. (1957). Spinal Cord Compression. Thomas, Springfield, Illinois.

Williams, H. M., Diamond, H. D., and Craver, L. F. (1958). The pathogenesis and management of neurological complications in patients with malignant lymphomas and leukemia. Cancer (Philad.), 11, 76-82. 